\title{
Ser-Estar-Fazer Docente: a epistemologia da prática do/a professor/a de Geografia
}

\author{
Being and Doing of the Teacher: the epistemology of Geography teachers' practice
}

Ser-Estar-Hacer Docente: la epistemología de la práctica del profesor de Geografía

Victória Sabbado Menezes ${ }^{1}$

https://orcid.org/0000-0003-2750-2820

\begin{abstract}
RESUMO: $O$ artigo apresenta o intento de discutir a epistemologia da prática do professor de Geografia com a finalidade de analisar as linhas epistemológicas da Geografia e da Educação que caracterizam o ser-estar-fazer docente. Para tanto, realizou-se uma revisão bibliográfica e uma pesquisa de campo por meio da observação simples das aulas de professores de Geografia do ensino básico estadual de um município do interior do Rio Grande do Sul e das aulas de estágio obrigatório de acadêmicos da licenciatura em Geografia de uma universidade federal do mesmo município. Quanto às dissonâncias entre estes grupos, destaca-se o uso de maior diversidade de recursos didáticos pelos acadêmicos e o fato dos professores não centrarem suas aulas apenas nos conteúdos geográficos em si, mas também visando uma formação integral dos alunos. No tocante às convergências, identificou-se um ensino marcado pela quase ausência da dialogicidade, bem como uma contradição epistemológica tanto da Geografia quanto da Educação em seus fazeres docentes. Contudo, a epistemologia da prática dos sujeitos apresenta a predominância do empirismo, o que contribui para a reprodução de um ensino de Geografia pouco significativo aos alunos, anunciando a necessidade de repensar as licenciaturas em Geografia não somente em termos metodológicos, mas, sobretudo, epistemológicos.
\end{abstract}

PALAVRAS-CHAVE: Ensino de Geografia. Epistemologia da prática. Formação docente.

ABSTRACT: This article aims to discuss the epistemology of geography teachers' practice in order to analyze the epistemological lines of Geography and Education that characterize the being and doing of the teacher. To that end, the research methods carried out were a literature review and a field research through simple observation of classes of geography teachers in a public school and classes of geography undergraduate students of a federal university in mandatory teaching practice in a town in Rio Grande do Sul. Both groups showed dissimilarities; namely, the undergraduate students draw on a wide range of teaching resources, and the teachers aim to their students' comprehensive development, not focusing their classes only on geographical content. Regarding the similarities, both groups lacked dialogicity in their teaching, and showed an epistemological contradiction of both Geography and Education in their work. Nevertheless, empiricism prevailed in the epistemology of the practice of teachers and academics, contributing to the reproduction of geography teaching with

\footnotetext{
${ }^{1}$ Doutorado em Geografia pela UFRGS (Universidade Federal do Rio Grande de Sul). Professora da UNESPAR (Universidade Estadual do Paraná, campus União da Vitória). E-mail: victoriasabbado@gmail.com.
} 
limited significance to students, revealing the need of rethinking geography teaching degrees not only regarding their methodology, but specially their epistemology.

KEYWORDS: Geography teaching. Epistemology of practice. Teacher education.

RESUMEN: Este artículo presenta el intento de discutir la epistemología de la práctica del profesor de Geografía con el fin de analizar las líneas epistemológicas de la Geografía y la Educación que caracterizan el ser-estar-hacer docente. Para tanto, se llevó a cabo una revisión bibliográfica y una investigación de campo con la observación simple de clases de profesores de Geografía de la enseñanza básica pública estadual de un municipio del interior de Rio Grande do Sul y de clases de prácticas obligatorias de estudiantes de profesorado en Geografía de una universidad federal del mismo municipio. En cuanto a las disonancias entre los grupos, se destaca que los académicos se valen de una mayor diversidad de recursos didácticos y los profesores no centran sus clases solamente en los contenidos geográficos, aspirando a una formación integral de los alumnos. En lo que toca a las convergencias, se identificó una enseñanza marcada por la casi ausencia de dialogicidad, y la existencia de una contradicción epistemológica tanto de la Geografía como de la Educación en el hacer docente. Sin embargo, la epistemología de la práctica de los sujetos presenta predominio del empirismo, lo que contribuye para la reproducción de una enseñanza de Geografía poco significativa para los alumnos, anunciando la necesidad de repensar los profesorados de Geografía, no solo en términos de metodología, sino también de epistemología.

PALABRAS CLAVE: Enseñanza de Geografía. Epistemología de la práctica. Formación docente.

\section{INTRODUÇÃO}

A reflexão concernente ao ensino de Geografia na contemporaneidade torna-se premente, tendo em vista o que se tem lido e observado nas escolas. Há quem afirme que o ensino de Geografia está em crise, porém deve-se considerar um contexto mais amplo, ou seja, a escola está em crise. Um ensino enciclopédico, mnemônico e sem significado para os alunos não é exclusividade da Geografia, de modo que atinge outros componentes curriculares. Isso põe em questão o papel da escola no que diz respeito à sua função social. Critica-se a escola por permanecer estagnada em um determinado período histórico que não corresponde à atualidade, pois tem formado sujeitos com dificuldades de desenvolver uma leitura crítica do mundo e atuar no contexto hodierno.

Os professores, em geral, também são alvo de críticas em função das práticas que realizam. Segundo a literatura acadêmica, grande parte dos docentes desenvolve práticas tradicionais e reprodutivistas que não colaboram para que os educandos sejam capazes de enfrentar o mundo complexo. Contudo, ressalta-se que mais do que pensar nas práticas pedagógicas, é necessário pensar o que está por trás delas, o que as origina, o que as fundamenta, a isto que se propõe este artigo, ou seja: investigar a epistemologia da prática do professor de Geografia. Nesse sentido, trata-se de uma produção científica associada ao campo do ensino de Geografia e formação de professores. 
Pressupõe-se que toda prática do professor provém das concepções que apresenta, isto é, de determinadas linhas teóricas da Educação e da Geografia, embora muitas vezes o mesmo não tenha consciência disso. Ao constatar fragilidades no ensino de Geografia, salienta-se a necessidade de pensar as concepções epistemológicas que sustentam o fazer pedagógico dos educadores. Por conseguinte, o presente artigo analisa a epistemologia da prática que embasa os professores e acadêmicos (futuros professores) de Geografia.

Os sujeitos da pesquisa são formados por dois grupos distintos: professores de Geografia em serviço e licenciandos em Geografia de uma universidade federal do interior do Estado do Rio Grande do Sul. Tem o intuito de analisar os professores para que se possa identificar a epistemologia que rege sua ação pedagógica e compreender alguns elementos que caracterizam o ensino de Geografia na realidade atual. Também fazem parte do estudo os licenciandos em Geografia, pois serão os professores que estarão em sala de aula "amanhã". Serão esses que irão definir a Geografia que será ensinada.

Por conseguinte, pretende-se pensar o ensino de Geografia a partir da realidade escolar. Parte-se do princípio que não é possível elaborar considerações sobre a Geografia escolar sem o diálogo com aqueles que a constroem diariamente nas instituições escolares. Da mesma forma, repensar a formação inicial docente exige o contato direto com os acadêmicos, futuros professores. Desse modo, não se pretende apresentar fórmulas mágicas para a Educação e para o ensino de Geografia, mas sim provocar questionamentos e reflexões de cunho epistemológico sobre a prática docente.

\section{TRILHA METODOLÓGICA}

O trilhar metodológico apresenta abordagem qualitativa, de maneira que o interesse central está nos processos e não nos produtos ou resultados. As estratégias adotadas nesta perspectiva visam identificar "[...] como o fenômeno acontece, como se manifesta, como é percebido, como é representado pelos atores etc. $O$ antes, $O$ durante e 0 depois são considerados, os passos, a trajetória, o percurso etc." (TEIXEIRA, 2009, p. 123). Os dados não são levantados para, necessariamente, comprovar hipóteses formuladas previamente, uma vez que o investigador qualitativo se dirige ao campo para conhecer e compreender a realidade do seu objeto de estudo.

Quanto às etapas da pesquisa, esta é formada por dois momentos: a pesquisa teórica e a pesquisa prática. No primeiro momento verifica-se uma aproximação da pesquisadora com a produção científica existente acerca do seu tema de pesquisa. Assim, realizou-se uma revisão bibliográfica a fim de fornecer um suporte teórico ao trabalho. A partir de um levantamento bibliográfico, foram estudadas obras de teóricos reconhecidos, principalmente 
na área de Ensino de Geografia, da Epistemologia da Geografia e da Educação (formação de professores), com o intento de garantir uma fundamentação teórica à investigação.

O outro momento corresponde à pesquisa de campo, um momento empírico, em que se busca uma aproximação com a realidade e o levantamento de informações e esclarecimentos sobre a temática de pesquisa proposta. Adotou-se a técnica de observação das aulas dos sujeitos da pesquisa a fim de investigar a epistemologia da prática dos mesmos. Esta é "[...] uma técnica de coleta de dados para conseguir informações e utiliza os sentidos na obtenção de determinados aspectos da realidade. Não consiste apenas em ver e ouvir, mas também em examinar fatos ou fenômenos que se deseja estudar" (MARCONI; LAKATOS, 2010, p. 173). A vantagem da observação em comparação às outras técnicas consiste no fato de que os fenômenos são percebidos e captados diretamente, sem intermediação. Por outro lado, a presença do observador pode provocar algumas modificações no comportamento dos sujeitos observados, afetando a espontaneidade dos mesmos. Cabe ao pesquisador atentar para as interferências que sua presença pode produzir na maneira de agir dos sujeitos observados e, assim, comprometer a sua pesquisa.

Em relação ao grau de participação, adotou-se a observação simples das aulas ministradas pelos professores e pelos acadêmicos no seu período de estágio. De acordo com esta técnica, o pesquisador observa a realidade assumindo a condição de um espectador, de maneira que não intervém diretamente no contexto observado. Contudo, esta prática não é neutra e por mais que não se queira interferir na dinâmica do fenômeno analisado, a própria presença do pesquisador no local de estudo, conforme supracitado, produz algumas perturbações. Segundo Moraes e Valente (2008, p. 43):

Assim o que o pesquisador observa depende também do que acontece em sua estrutura; e mais: todo pesquisador, consciente ou não, participa da realidade que pretende explicar [...]. Ao descrever sua realidade, 0 pesquisador interage com ela, modificando-a e também sendo por ela modificado, estruturalmente.

Utilizou-se um diário para tomar nota das observações, onde foram registrados os elementos que estavam de acordo com o roteiro previamente elaborado, mas também outras informações consideradas relevantes foram acrescentadas. Todas as anotações no diário ocorreram durante o momento da observação a fim de que nenhuma questão interessante percebida fosse esquecida. Cabe salientar que além das descrições da observação, também foram anotadas as reflexões que se desencadearam durante esta atividade.

As observações foram concluídas quando se percebeu que não havia novas informações, quando se constatou uma repetição e um padrão nas práticas pedagógicas 
dos sujeitos. Assim, o número de observações não foi o mesmo com cada um dos sujeitos pesquisados, tendo em vista que a(s) epistemologia(s) da prática do professor é algo que, na maioria dos casos, não é fácil de captar e investigar. Foram observadas um total de 86 aulas, sendo 60 aulas dos professores e 26 aulas dos acadêmicos.

Cabe esclarecer que o universo de pesquisa é formado por professores do Ensino Fundamental e/ou Médio de escolas estaduais de Pelotas, um município do interior do Rio Grande do Sul e por acadêmicos formandos do curso de Licenciatura em Geografia de uma universidade federal do respectivo município. A amostra é composta por um total de 10 sujeitos, isto é, compreende cinco professores e cinco acadêmicos. É preciso esclarecer que não se tem a pretensão de generalizar os resultados desta análise e retratar a realidade educacional da totalidade do município. As análises que serão construídas representarão somente o universo analisado.

Percebe-se que o número de aulas observadas dos estagiários foi inferior ao dos professores, tendo em vista se tratar de um período delimitado para a realização do estágio curricular obrigatório. A quantidade de observações das aulas dos professores não foi prédeterminada. Ocorreram enquanto sentia-se a necessidade de levantar mais dados e foram finalizadas quando se constatou certo padrão no fazer pedagógico dos docentes. Já os acadêmicos foram observados até o final do seu estágio supervisionado.

É importante destacar que a análise das práticas dos professores é resultado de um acompanhamento diário das aulas dos mesmos. Observou-se os professores em diferentes turmas e séries/anos. Isso permitiu a construção de uma investigação mais completa do fazer pedagógico destes sujeitos e uma melhor compreensão da rotina do professor e da dinâmica estabelecida nas escolas. Diferentemente da pesquisa com os estagiários que tinham duas aulas por semana, o que representava um momento pontual na instituição, a pesquisa com os docentes propiciou uma imersão no espaço escolar. Assim, pôde-se sentir e respirar a escola seja nas salas de aula, nas salas de vídeo, nos corredores, na sala dos professores ou no pátio. Através do trabalho de campo, vivenciou-se o que se passa no diaa-dia do educador.

As observações das aulas dos sujeitos da pesquisa tinham o intento de analisar sua ação pedagógica e buscar identificar sua epistemologia da prática. Para tanto, o olhar sobre as práticas pedagógicas foi direcionado para os seguintes pontos: metodologia de ensino, recursos didáticos, relação professor-aluno, postura do professor no processo de ensinoaprendizagem, atividades desenvolvidas, papel do aluno, comportamento dos alunos eformas de avaliação. As observações foram orientadas para investigar estes aspectos, porém assumiu-se uma postura aberta. Tinha-se um roteiro, mas objetivou-se analisar todo o processo de dinâmica da aula. 
Ao discorrer acerca da prática docente não é possível desconsiderar a figura do aluno. Nesse sentido, o sujeito aluno e a turma como um todo também foram observados com atenção a fim de compreender a ação pedagógica dos professores e acadêmicos. Cabe pontuar que a faixa etária dos professores varia entre 31 e 50 anos, tempo de docência entre três e 22 anos e a carga horária média de 40 horas semanais. A faixa etária dos acadêmicos encontra-se entre 23 e 41 anos, e todos estavam realizando o estágio supervisionado no Ensino Médio.

Portanto, analisou-se as práticas pedagógicas dos sujeitos da pesquisa com o intuito de aproximar-se da compreensão da epistemologia da prática adotada pelos mesmos a fim de provocar reflexões concernentes ao fazer docente em Geografia. Tal processo analíticointerpretativo fundamenta-se em determinados referenciais teóricos, de modo a proporcionar a articulação entre teoria e empiria com a finalidade de contribuir para a discussão referente ao ensino de Geografia no contexto contemporâneo.

\section{POR ENTRE SABERES E PRÁTICAS: A COMPOSIÇÃO DO SER DOCENTE}

A necessidade de (re)pensar a formação docente está associada ao fato de que o trabalho dos educadores, em geral, tem sido posto em questão por não alcançar o desejado para uma educação de qualidade. Apesar de existirem exceções, predominam práticas pedagógicas tradicionais, conteudistas e reprodutivistas nas instituições educativas. Este ensino conservador, ainda hegemônico nas salas de aula, é oriundo da própria história do ensino escolar. Ou seja, o ensino escolar moderno passou por uma evolução lenta, assim como o processo de profissionalização da docência, de maneira que para entender o quadro atual é preciso resgatar este processo histórico.

O ensino escolar é marcado por três idades que correspondem a determinados períodos históricos. Na primeira fase, que remonta aos séculos XVI e XVIII na Europa, o ensino é concebido como uma vocação. Assim, não compreende uma profissão propriamente dita, mas algo de nascença, como um chamado "divino", "superior". Deve-se salientar que mesmo com a modernização, esta visão vocacional do ensino não desapareceu, pois ainda se observam alguns sujeitos afirmarem que são professores por vocação.

A idade do ensino como trabalho inicia-se a partir da separação entre os Estados nações e as lgrejas por volta dos séculos XIX e XX. A relação dos professores com o trabalho deixa de ser uma vocação para tornar-se uma relação que envolve contrato e salário. Além disso, criam-se redes escolares públicas e laicas. Conforme Tardif (2013, p. 556), "[...] simultaneamente à criação dessas redes, os Estados impõem a obrigação da 
presença das crianças na escola: a educação pública torna-se, portanto, pouco a pouco obrigatória".

A terceira idade, a idade da profissão, desenvolveu-se a partir do século $X X$ em consonância com as universidades modernas que visavam formar profissionais nas diferentes áreas pautando-se nos conhecimentos produzidos pela ciência. Assim, a profissionalização do ensino tinha como objetivo fazer com que os professores realizassem suas práticas com base em conhecimentos científicos. Contudo, de acordo com Tardif (2013, p. 562), "[...] a idade da profissão ainda está em gestação". A proletarização, a diversificação e a complexificação do trabalho docente representam fatores que têm limitado esta profissionalização. Isso acarreta o desafio que se enfrenta atualmente, a dificuldade de esclarecer os conhecimentos imprescindíveis ao professor e de colocá-los em prática.

No que diz respeito aos saberes do educador, é interessante, primeiramente, desmistificar algumas ideias preconcebidas. Estas existem devido à falta de definição dos saberes envolvidos no exercício dessa profissão. Desse modo, surgem algumas ideias equivocadas, segundo Gauthier et al. (1998), como a noção de que basta conhecer o conteúdo para ser professor, basta ter talento, basta ter bom senso, basta ter experiência, basta seguir a intuição e basta ter cultura. São visões isoladas que reduzem a atividade do professor à necessidade de um conhecimento apenas e não de um conjunto de saberes. Defende-se a importância de cada um destes conhecimentos, porém a utilização de somente um deles não é suficiente ao trabalho do professor. Ademais, não basta apresentar um conjunto de conhecimentos, deve-se saber utilizá-los.

Nessa perspectiva, elimina-se a complexidade inerente ao trabalho docente que exige uma diversidade de conhecimentos, bem como impede a constituição de um saber profissional que vise abranger os distintos saberes. Deve-se ressaltar que atualmente ainda prevalecem algumas destas ideias preconcebidas, o que evidencia o desafio de elaborar um arcabouço de conhecimentos do professor e profissionalizar a atividade docente. Dessa forma, reitera-se ser pertinente "[...] conceber o ensino como a mobilização de vários saberes que formam uma espécie de reservatório no qual o professor se abastece para responder a exigências específicas de sua situação concreta de ensino" (GAUTHIER et al., 1998, p. 28).

Para Tardif (2014), a profissionalização do ensino está relacionada à tentativa de renovar os fundamentos epistemológicos do ofício do professor. Para tanto, é preciso construir um repertório de conhecimentos específico ao ensino a fim de que se tenha a clareza no que se refere aos saberes dos professores, a maneira como são construídos e ao papel da formação na integração destes saberes. O autor ainda destaca que o estudo destes conhecimentos não pode, indubitavelmente, ser desvinculado das situações reais de ensino, desconsiderando as condições concretas em que o trabalho é realizado. 
Com o intento de analisar estes saberes articulando-os com a prática docente, Tardif (2014) discorre acerca de uma epistemologia da prática profissional. Esta epistemologia considera a prática como um local de produção e transformação de saberes por apresentar determinadas condições e fatores que não são proporcionados na formação teórica realizada na universidade, por exemplo. Assim, busca-se desvendar o conjunto de conhecimentos que são mobilizados pelos educadores em sua atividade, qual a natureza destes saberes, como são utilizados na prática e de que maneira interferem na constituição da identidade docente.

A epistemologia da prática valoriza a prática profissional como um momento em que o educador constrói conhecimento a partir da análise e reflexão desta. Diz respeito a um conhecimento produzido na ação e sobre a ação. Desse modo, não a precede, mas é elaborado durante seu fazer pedagógico. Monteiro (2012, p. 133) esclarece que:

[...] a epistemologia da prática refere-se à produção (technê) de um saber, permitido por um outro olhar (thôréô), sobre o que e quê é feito (prássô). Por isso, é possível teorizar sobre a prática, pois essa é observável; toda prática (prássô) submetida a um novo olhar (theôréô) pode ser modificada.

Uma epistemologia da prática apresenta sentido à medida em que considera teoria e prática como elementos inseparáveis. O conhecimento da prática pode ser alimentado pelas teorias da Educação a fim de que o professor possua um suporte de saberes que possam contribuir nas situações concretas de ensino que irá se deparar. Através da articulação entre os conhecimentos teóricos e os conhecimentos práticos, é possível que ambos sejam ressignificados. A partir disso, o docente poderá enxergar sua prática com um outro olhar visando reconfigurá-la.

São inúmeros os saberes necessários ao professor para desenvolver seu trabalho, o que torna esta profissão extremamente complexa e ratifica a responsabilidade dos cursos de formação de professores. Qual seria o conjunto de saberes importantes ao educador? Conforme Gauthier et al. (1998), o repertório de conhecimentos é composto pelo: saber disciplinar, saber da experiência, saber curricular, saber das ciências da educação, saber da ação pedagógica e saber da tradição pedagógica.

Diante disso, torna-se necessário lançar um olhar para as práticas pedagógicas dos professores de Geografia a fim de compreender sua epistemologia da prática. Isso quer dizer que o fazer docente envolve produção e mobilização de saberes, bem como está ancorado em determinadas concepções de Geografia e de Educação. Portanto, não é possível dissociar o ser-estar-fazer docente da corrente epistemológica com a qual se identifica e que, por consequência, expressa no ato pedagógico sua visão de mundo, de conhecimento, de ensino e de Geografia. 


\section{A EPISTEMOLOGIA DA PRÁtICA EM QUESTÃO: OS FAZERES DOCENTES DE PROFESSORES E FUTUROS PROFESSORES DE GEOGRAFIA}

As práticas pedagógicas dos sujeitos da pesquisa foram analisadas com o intuito de identificar os pontos em comum e os pontos divergentes observados entre o fazer pedagógico dos dois grupos: professores e estagiários. Primeiramente, é importante salientar que estes grupos se encontram em momento distintos da caminhada acadêmicaprofissional. Enquanto os professores já estão graduados e possuem alguns anos de carreira docente, os acadêmicos estavam em uma etapa de extrema relevância em sua formação inicial, qual seja: o estágio supervisionado.

O estágio representa o momento em que despertam para a docência e, muitas vezes, é um divisor de águas, visto que a partir da experiência passam a ter mais clareza se querem ou não seguir na profissão docente. Contudo, apesar de ser um período da graduação destinado à experimentação prática, notou-se que os acadêmicos não ousaram em suas aulas. Ou seja, a preocupação demasiada com o conteúdo e com a aceitação dos alunos à sua presença resultou em práticas educativas pouco inovadoras e reflexivas. São estas inquietações provenientes das observações das práticas dos estagiários que alertam para que se deixe de concretizar o que Cazuza já havia constatado: "Eu vejo o futuro repetir o passado, eu vejo um museu de grandes novidades [...]" (O TEMPO..., 1988). Tal quadro é destacado por Cavalcanti (2019) que tece um histórico concernente ao ensino de Geografia no Brasil, esclarecendo suas diferentes fases. Para a autora, a fase atual, a qual está em consonância com o que foi constatado na presente pesquisa, pode ser explicada pelos seguintes fatores:

No contexto brasileiro atual, nessa última década - 2011/2019, acentua-se a orientação neoliberal das políticas para a educação escolar como um todo e para o ensino de Geografia. Isso significa uma vinculação mais intensa a demandas econômicas, nacionais e internacionais, a agências de financiamento, a pautas de resultados na ampliação de vagas, a diminuição do analfabetismo, e não a processos formativos mais amplos. Esse contexto afeta diretamente a prática escolar com a disciplina Geografia, dificultando trabalhos mais voltados ao cumprimento de sua tarefa de contribuir com a formação humana cidadã ativa, crítica e participativa (CAVALCANTI, 2019, p. 43).

Com a finalidade de esclarecer o que as observações das aulas permitiram perceber e refletir acerca da epistemologia da prática destes sujeitos, inicia-se com os pontos que marcaram as distinções entre os fazeres docentes dos acadêmicos e dos professores em serviço. No que concerne às dissonâncias, percebeu-se que os acadêmicos empregaram uma diversidade maior de recursos (mapas, cartas topográficas, vídeos, globo, datashow - 
apresentação de slides) e metodologias (trabalho em grupo, atividade em dupla, aula no pátio) em sala de aula, ao passo que os professores adotaram uma sistemática mais restrita. Dessa forma, as aulas dos educadores eram mais previsíveis aos seus alunos, visto que raramente havia elementos diferentes. Consequentemente, a possibilidade de atrair 0 interesse e envolver os educandos em aula era menor sem o emprego de diferentes recursos e metodologias.

Cabe salientar que a adoção de variados recursos didáticos e metodologias é positiva nos aspectos supracitados, porém não garante um processo de construção do conhecimento. Muitas vezes, são utilizadas múltiplas técnicas para tornar a aula diferente ou então se substitui a exposição do professor por um vídeo, por exemplo. Assim, não se propicia a aprendizagem, pois a aula torna-se apenas aparentemente inovadora, sem provocar o debate de ideias, a dúvida, o diálogo e a reflexão. Segundo Vlach (1991, p. 80), "[...] ensinar é, antes de mais nada, o trabalho do aluno com o saber, sob a mediação do professor". Se o educando não é provocado a pensar, não há aprendizagem.

Observou-se que os professores utilizaram o livro didático (poucas vezes) e os estagiários não. Inclusive, os acadêmicos manifestavam em aula que queriam "fugir" do livro didático, o que evidencia sua visão de que adotar o livro está associado à ideia de que as aulas serão necessariamente mecânicas e reprodutivistas. Contudo, era comum os acadêmicos encherem o quadro de matéria para os alunos copiarem. Na grande maioria das vezes explicavam o conteúdo colocado no quadro, mas nem sempre este era problematizado. Nesse sentido, destaca-se a necessidade de repensar os fundamentos epistemológicos que embasam a prática docente, visto que a crítica ao livro didático não deve ser direcionada ao uso ou não uso e sim à maneira como é utilizado. O mesmo vale para o conteúdo no quadro. Logo, a questão principal não se centra no instrumento adotado, mas na forma como o professor explora este instrumento e desenvolve sua prática educativa.

Constatou-se que os educadores apresentavam uma relação mais próxima e amigável com os educandos do que os estagiários com seus alunos. Evidente que o contato dos professores com os estudantes é bem maior do que os acadêmicos que desenvolvem o estágio em um período curto de tempo. Entretanto, notou-se que principalmente dois acadêmicos buscavam manter distanciamento dos alunos. Ficou claro durante as observações que uma relação tranquila e de amizade com a turma não significa ausência de regras e respeito entre os sujeitos da aprendizagem.

Todavia, é digno de nota que uma boa relação professor-aluno não garante uma interação pedagógica. Uma boa relação não produz, necessariamente, uma aula que estimule a criatividade, criticidade e autonomia dos alunos. Diante disso, como fortalecer 
esse ponto de comunicação e afeto entre educador-educandos no sentido de provocar uma tensão cognitiva? Construir uma relação harmônica e amigável já representa uma vantagem para o professor desenvolver seu trabalho, mas é necessário que seja aproveitada no processo de ensino-aprendizagem. Pela proximidade com os alunos, o professor pode incentivá-los a participar da aula, contribuir nas discussões, resolver situações-problema sem que se sintam intimidados, receosos de errar, envergonhados. Por isso, uma relação horizontal e de confiança pode possibilitar a troca de conhecimentos entre professor e alunos.

Notou-se que os estagiários desenvolviam suas práticas educativas visando o curto prazo pelo limite de aulas que possuíam para ministrar. O intuito era apresentar o conteúdo de Geografia para que os estudantes o compreendessem. Já a maioria dos professores preocupava-se com a formação completa dos alunos. Embora também concedessem grande importância ao conteúdo, não restringiam suas aulas a abordar especificamente o conhecimento geográfico curricular. Estes realizavam seu trabalho atentando para a formação intelectual, mas também pessoal dos educandos, tratando de questões pertinentes à valores, comportamentos e atitudes. Por outro lado, observou-se muito tempo desperdiçado em algumas aulas dos professores, em que ficava um vazio, nada acontecia. Os acadêmicos, por sua vez, aproveitavam mais o período de aula, exigindo atenção e participação dos alunos.

Em relação aos pontos em comum, tanto professores quanto estagiários apresentaram dificuldades para construir um ambiente propício à construção e reconstrução do conhecimento. A quase ausência de dialogicidade foi uma das questões preocupantes percebidas nas aulas de todos os sujeitos da pesquisa, o que significa que a relação professor-aluno não é estabelecida de modo a garantir a interação pedagógica e a troca de saberes. Em pouquíssimas ocasiões houve diálogo e, quando havia interação, esta era caracterizada por perguntas do educador e respostas dos alunos. Nem sempre estas indagações do professor eram provocadoras e desequilibravam o pensamento dos alunos. Essa atitude tende a produzir aulas mecânicas e reprodutivistas. É importante enfatizar que a dialogicidade não significa a eliminação de momentos explicativos do professor, mas como afirma Freire (1996, p. 86):

O fundamental é que o professor e alunos saibam que a postura deles, do professor e dos alunos, é dialógica, aberta, curiosa, indagadora e não apassivada, enquanto fala ou enquanto ouve. O que importa é que professor e alunos se assumam epistemologicamente curiosos.

Para dialogar com o educando, outro fator é imprescindível: ouvir o aluno. Não basta que o aluno fale, pois é fundamental que o educador realmente o escute, considere suas 
contribuições e estabeleça de fato uma interação. Esta postura permitirá que o professor possa organizar e planejar suas aulas pensando no aluno a partir do aluno, conforme considera Marques (2005). Logo, conhecer processos de aprendizagem torna-se fundamental para que se possibilite uma aprendizagem significativa, pois na medida "[...] em que o professor se coloca na posição de pesquisar em sala de aula que ele consegue superar o seu egocentrismo, entender o pensamento do aluno e coordenar os diferentes pontos de vista que se configuram nesse espaço escolar" (MARQUES, 2010, p. 61).

No que diz respeito à visão de Geografia, professores e acadêmicos expressaram em sala de aula uma perspectiva predominantemente conteudista. Alguns ressaltavam a importância da disciplina para a leitura de mundo dos educandos, mas suas práticas não podem ser definidas por somente uma linha teórica da Geografia. Percebeu-se que o ensino se caracterizava, em alguns momentos, mais pela Geografia Tradicional e, em outros, pela Geografia Crítica ou pela Geografia Humanista. A Geografia Teorético-Quantitativa e Cultural não estiveram presentes nas práticas educativas observadas.

Cabe ressaltar que quase a totalidade dos sujeitos da pesquisa buscava estabelecer relações da temática trabalhada com o contexto local e apresentavam exemplos concretos para facilitar a compreensão dos educandos. Dessa maneira, tinha-se o intento de vincular o conteúdo à realidade vivenciada pelos educandos no seu cotidiano, o que se aproxima de algumas ideias próprias da Geografia Humanista. Contudo, um elemento chave para o desenvolvimento de uma Geografia Crítica e uma aprendizagem significativa assentada no processo de construção do conhecimento esteve pouco presente, qual seja: a reflexão. 0 conteúdo era apresentado, explicado pelo professor, mas raramente era questionado e problematizado. Além disso, não se privilegiava a discussão acerca do tema nem o confronto entre os diferentes pontos de vista dos educandos. Como diz a música "[...] focado no seu mundo qualquer homem imagina muito menos do que pode ver" (SIMPLES..., 2015). Por conseguinte, ao não proporcionar diferentes olhares e ângulos sobre uma mesma problemática torna-se difícil ao aluno desenvolver sua criticidade, ampliar seus horizontes de análise e construir sua autonomia. Reitera-se que "[...] se se pretende fazer Geografia crítica, há que se abrir à Alteridade, ao Plural. Ou existe apenas uma vereda para a crítica da Geografia tradicional?" (VLACH, 1990, p. 48).

Quanto à epistemologia da Educação que rege a prática dos sujeitos, tanto professores quanto acadêmicos executaram seu fazer pedagógico ancorado em uma mescla entre empirismo e construtivismo, assim como uma mistura de pedagogia diretiva e relacional (BECKER, 1993). A epistemologia apriorista e a pedagogia não-diretiva não foram percebidas na ação pedagógica dos sujeitos, pois todos assumiram a posição de conduzir o processo educativo, de modo que não defendiam a ideia de que as estruturas do 
conhecimento já vêm programadas na bagagem hereditária dos alunos. Todos tinham claro que o aluno não aprende por si mesmo, por isso deveriam ser ensinados.

As práticas pedagógicas observadas eram marcadas pela perspectiva de que 0 professor deve transferir conhecimento para o aluno, mas este não é concebido como tábula rasa. O aluno dispõe de conhecimentos prévios, porém estes são considerados apenas para auxiliar na introdução do conteúdo que o professor irá trabalhar. Assim, não se verifica uma interação radical entre o educador e a turma. Ao mesmo tempo em que não há coerção, não há autoritarismo, não há silêncio absoluto, também não há desacomodação, não há diálogo efetivo, não há (re)construção do conhecimento e não há participação dos alunos nas decisões sobre a organização das aulas através de propostas e sugestões.

As práticas educativas de acadêmicos e professores estão em consonância ao considerarem o conteúdo geográfico como um fim. A interação entre professor-aluno limitava-se à perguntas e respostas, acarretando na repetição do conteúdo. Dessa forma, a troca entre os sujeitos da aprendizagem não possibilitava a construção e descoberta do novo. Costella (2011) esclarece que conteúdo é diferente de conhecimento, de maneira que para conhecer é necessário significar o conteúdo. Portanto, a construção do conhecimento perpassa um processo de significação do conteúdo, o que exige do educador o papel de provocador para desacomodar o pensamento do educando. Ao pautar as práticas na mera transmissão do saber aos alunos, "[...] sem provocar as ações internas de busca nos mesmos, estamos literalmente queimando etapas importantes da cognição. A descoberta do novo a partir do conhecido e as buscas por maiores complexidades dão sentido a aprendizagem" (COSTELLA, 2011, p. 233).

Observou-se que aulas destinadas a estimular a capacidade criativa, a crítica e a reflexão dos estudantes foram pontuais. Esta percepção vai ao encontro do que Cavalcanti (2019, p. 47) aponta ao salientar que ainda "[...] permanecem as atividades que reduzem o exercício intelectual dos alunos, sendo este basicamente o de repetir informações, explicações esquemáticas, definições/classificações sobre os temas que lhes são apresentados". A exceção foi um projeto proposto por uma professora que se tratava de uma experiência semelhante ao trabalho dos recenseadores do IBGE, a qual era realizada ao longo de todo o ano letivo com o $7^{\circ}$ ano do Ensino Fundamental. Isso demonstra que a prática tradicional está entranhada, naturalizada no fazer docente.

Percebeu-se, sobretudo nos estagiários, que mesmo defendendo o construtivismo "[...] não sabem que decisões tomar frente às situações mais conflitantes e, por isso, presos a esquemas clássicos e tradicionais, acabam por reproduzir condutas heterônomas (autoritárias)" (KEBACH, 2010, p. 44). Em geral, nos momentos de tensão ou quando pensam que estão perdendo o controle da turma, recorrem a atitudes próprias de uma 
prática conservadora e de uma pedagogia diretiva. Revela-se, assim, a necessidade de que se provoque uma desnaturalização da prática tradicional pelo sujeito professor.

A análise das práticas dos sujeitos da pesquisa infere que não há uma única epistemologia responsável por orientar o fazer pedagógico do educador. Mesmo com as diferentes correntes de pensamento da ciência geográfica (Geografia Tradicional, Geografia Teorético-Quantitativa, Geografia Crítica, Geografia Humanista, Geografia Cultural) e das linhas pedagógicas e epistemológicas da Educação (Empirismo e pedagogia diretiva, apriorismo e pedagogia não-diretiva, construtivismo e pedagogia relacional), as quais muitas vezes se opõem umas às outras, não é possível enquadrar o professor somente em uma determinada perspectiva. É preciso enfatizar que não se teve o intuito de classificar os sujeitos em modelos rígidos. Contudo, na busca de aproximações com determinadas vertentes, verificou-se a presença constante da contradição. Para compreendê-la, Morin e Viveret (2013, p. 9) contribuem ao esclarecer que:

Para entender o que acontece e o que vai acontecer no mundo, é preciso ser sensível à ambiguidade. O que é a ambiguidade? Ela se traduz pelo fato de que uma realidade, pessoa ou sociedade se apresenta sob o aspecto de duas verdades diferentes ou contrárias, ou então apresenta duas faces, não se sabendo qual é a verdadeira.

A ambiguidade se revela na prática educativa do educador, sejam estagiários ou professores em serviço. Não se pode afirmar a existência da epistemologia do professor, no singular, mas sim das epistemologias que, inclusive, se contradizem. Desse modo, não se pode definir a epistemologia da prática do professor a partir da orientação de uma corrente epistemológica da Geografia e da Educação. A observação das aulas dos sujeitos da pesquisa demonstrou que sua epistemologia da prática é plural e diversa, o que evidencia a complexidade das práticas de ensino em sua caracterização. Contudo, ainda que se perceba esta multiplicidade epistemológica no fazer docente não se pode desconsiderar que há a predominância de determinada linha epistemológica, sobretudo da Educação, a qual se refere ao empirismo. Destarte, torna-se necessário que esta constatação seja problematizada nas licenciaturas em Geografia com o fito de desconstruir e problematizar práticas pedagógicas que privilegiam a transmissão e pouca reflexão no processo de ensino-aprendizagem em Geografia no espaço escolar.

Nesse sentido, repensar a formação inicial de professores de Geografia passa pelo fortalecimento da profissionalização da docência. Conforme Nóvoa (2017, p. 1131), "[...] não pode haver boa formação de professores se a profissão estiver fragilizada, enfraquecida. Mas também não pode haver uma profissão forte se a formação de professores for desvalorizada e reduzida apenas ao domínio das disciplinas a ensinar ou das técnicas 
pedagógicas". Refletir acerca da epistemologia da prática docente significa aproximar-se dos saberes docentes mobilizados no cotidiano do trabalho de sala de aula a fim de que sejam problematizados à luz do arcabouço de conhecimentos profissionais. Portanto, a qualificação do ensino de Geografia deve estar acompanhada de uma formação de professores que seja concebida como uma formação profissional universitária, a qual dê legitimidade à docência enquanto profissão.

\section{CONSIDERAÇÕES FINAIS}

A principal constatação decorrente desta investigação corresponde à existência de contradição epistemológica. Notou-se que as práticas pedagógicas dos sujeitos não são orientadas por uma única vertente da Geografia e da Educação. Desse modo, não é possível classificar um professor como representante de um determinado modelo epistemológico e/ou pedagógico. A prática docente é muito mais que somente empirista ou apriorista ou construtivista, assim como a Geografia trabalhada muitas vezes não é exclusivamente Tradicional ou Quantitativa ou Crítica ou Humanista ou Cultural. Não é só, mas é também. Não é isso ou aquilo, mas é isso e aquilo. Logo, a prática pedagógica é composta de elementos provenientes de distintas correntes de pensamento, ainda que estas aparentem ser antagônicas.

Verificou-se que tanto os professores quanto os acadêmicos apresentam, em geral, uma visão conteudista de Geografia em sua ação docente. Teve-se dificuldade em perceber a(s) perspectiva(s) da ciência geográfica que embasavam suas práticas, tendo em vista o enfoque que concediam aos conteúdos curriculares. Na grande maioria das vezes, os conteúdos geográficos eram concebidos como fim do processo educativo. Percebeu-se que o grupo de acadêmicos era mais preocupado em abordar e, nas palavras de alguns destes sujeitos, transmitir os conteúdos geográficos aos alunos do que o grupo de professores. Este último, embora atentasse para o tratamento dos conteúdos, preocupava-se claramente com a formação humana, isto é, com a formação integral dos educandos.

Observou-se nas aulas de acadêmicos e professores que, na grande maioria das vezes, as práticas construtivistas são pontuais. Considera-se que ainda há uma hegemonia do empirismo em sala de aula, mesmo quando o sujeito defende ideias contrárias a esta perspectiva, acarretando em uma contradição entre teoria e prática. E por que isso acontece? Atribui-se esta questão à naturalização do empirismo. Isto é, ainda que ao longo da licenciatura o sujeito construa noções de uma Educação Crítica e passe a defender um ensino dialógico e pautado na construção do conhecimento, isso não garante que desenvolverá práticas educativas de acordo com esta linha de pensamento, uma vez que a formação inicial constitui apenas uma das fontes dos conhecimentos docentes. A história de 
vida escolar e as vivências como aluno geralmente são marcadas pela presença da epistemologia empirista. Assim, as experiências empiristas na condição de aluno são, geralmente, muito mais frequentes que as experiências construtivistas. Logo, superar o modelo de formação da educação básica é extremamente difícil.

Por consequência, provocar esta desnaturalização do empirismo refere-se a um processo longo a ser realizado pelo sujeito educador. A clareza das concepções de Educação e de Geografia, bem como dos objetivos que se visa alcançar no ensino são necessários, porém insuficientes. É essencial que as concepções teóricas estejam articuladas à epistemologia da prática docente. Isso pressupõe superar a visão dicotômica entre teoria e prática. Desse modo, a prática não se restringe à aplicação da teoria. Pelo contrário, tanto a teoria quanto a prática produzem saber e são complementares. Nesse sentido, a formação inicial deve ser repensada a fim de formar um professor pesquisador e reflexivo.

No que diz respeito às linhas pedagógicas e epistemológicas da Educação, deve-se destacar que o predomínio do empirismo não resultou na prática exclusiva de uma pedagogia diretiva. Os fazeres pedagógicos dos acadêmicos e professores não incluiu a pedagogia não-diretiva, mas caracterizavam-se por elementos da pedagogia diretiva e relacional. Foi demasiadamente positivo perceber que nas práticas de todos os sujeitos pesquisados não foi exercido o autoritarismo. Essa constatação representa um avanço significativo ao notar uma relação muito boa, tranquila e, em muitos casos, próxima, entre educador e educandos.

Entretanto, a boa relação observada entre os sujeitos da aprendizagem não era direcionada para efetivar uma interação mais intensamente cognitiva e a troca de conhecimento. Chamou a atenção que o diálogo dificilmente era estabelecido em sala de aula. Embora não houvesse uma relação autoritária e/ou coercitiva do professor sobre os alunos, percebeu-se muitas vezes certo conformismo de ambas as partes. Poucas perguntas eram elaboradas durante a aula, tanto pelos alunos quanto pelo professor, o que pouco estimulava a instauração do debate de ideias. Em momentos ociosos ou nos minutos finais da aula os discentes sentiam-se mais à vontade e expunham suas dúvidas e questionamentos, porém essa possibilidade de troca de saberes não era explorada pelo educador. Logo, notava-se nos estudantes uma curiosidade latente que era manifestada em determinados momentos. Mas por que os professores a desconsideravam como um princípio educativo? Seria falta de perspicácia para reconhecer esses momentos férteis de aprendizagem, cansaço de final de aula ou desinteresse?

Percebeu-se que, embora em raros momentos de aula, a curiosidade e a dúvida existem sim na mente dos alunos. Esses elementos tão essenciais para o desenvolvimento 
de um processo de ensino-aprendizagem significativo aos educandos não foram eliminados, mesmo com uma tradição escolar que pouca estimula a formulação de perguntas. Torna-se necessário resgatá-los, de maneira que sejam oferecidas as condições que encorajem a expressão dos alunos quanto aos seus interesses, questionamentos e incertezas. No entanto, foi comum nas práticas educativas dos sujeitos pesquisados haver pouca exigência e provocação visando a participação dos educandos. Em raras ocasiões foram estimulados a sair de sua zona de conforto, o que impedia a instauração de uma tensão cognitiva. $O$ conteúdo curricular era apresentado à turma sem ser problematizado, mas como algo pronto e acabado. Assim, sem a problematização não se desencadeava o confronto de pontos de vista e, consequentemente, as aulas transcorriam com pouca reflexividade. Eis aqui uma questão preocupante: preza-se o conteúdo e esquece-se da reflexão. Como desenvolver uma aprendizagem significativa sem reflexão?

Não se podem desconsiderar os inúmeros entraves ao trabalho docente, os quais foram observados e também relatados pelos professores e acadêmicos. Entre os principais obstáculos que dificultam o exercício da docência estão: a estrutura precária da escola, a desvalorização salarial e moral do professor, a falta de recursos didáticos, a realização de aulas paralelas e a falta de apoio familiar aos alunos. Além disso, percebe-se a perda do espaço da escola como lócus de trabalho e estudo, bem como a perda de status dos professores como uma autoridade que mereça ser ouvida, acarretando na menor professoralidade dos mesmos. A escola tem sido mais um espaço de socialização do que de estudo. Estes obstáculos estão relacionados às questões estruturais provenientes de um modelo de sociedade pautado em um sistema socioeconômico desigual e excludente que interferem na Educação e no trabalho diário dos professores. Ao mesmo tempo, este quadro não pode servir como justificativa para a comodidade dos docentes.

Portanto, buscou-se alcançar as raízes do fazer docente a fim de propiciar reflexões acerca da epistemologia da prática do professor de Geografia para que se possa repensar as práticas de ensino desenvolvidas na contemporaneidade e, quiçá, modificá-las e transformá-las visando sua qualificação. Contudo, esse desejo de transformação somente é possível se for alimentado pela utopia. Cabe a nós, professoras e professores de Geografia, atentarmos para as amarras que pretendem imobilizar nossos movimentos docentes, assumirmos nosso inacabamento e atuarmos com coerência aos princípios que defendemos. Sejamos, então, mais autônomos e ousados na nossa maneira de ser-estar no mundo e na docência. 


\section{REFERÊNCIAS}

BECKER, Fernando. A epistemologia do professor: o cotidiano da escola. Petrópolis: Vozes, 1993.

CAVALCANTI, Lana de Souza. Pensar pela geografia: ensino e relevância social. Goiânia: C\&A Alfa Comunicação, 2019.

COSTELLA, Roselane Zordan. Competências e habilidades no contexto da sala de aula ensaiando diálogos com a teoria piagetiana. Cadernos do Aplicação, Porto Alegre, v. 24, n. 1, p. 225-240, jan./jun. 2011.

FREIRE, Paulo. Pedagogia da autonomia: saberes necessários à prática educativa. São Paulo: Paz e Terra, 1996.

GAUTHIER, Clermont et al. Por uma teoria da pedagogia: pesquisas contemporâneas sobre o saber docente. ljuí: EdUNIJUÍ, 1998.

KEBACH, Patrícia Fernanda Carmem. O professor construtivista: um pesquisador em ação. In: BECKER, Fernando; MARQUES, Tania Beatriz Iwaszko (org.). Ser professor é ser pesquisador. Porto Alegre: Mediação, 2010. p. 43-54.

MARCONI, Marina de Andrade; LAKATOS, Eva Maria. Fundamentos de metodologia científica. São Paulo: Atlas, 2010.

MARQUES, Tania Beatriz Iwaszko. Do egocentrismo à descentração: a docência no ensino superior. 2005. Tese (Doutorado em Educação) - Programa de Pós-Graduação em Educação - Faculdade de Educação, Universidade Federal do Rio Grande do Sul, Porto Alegre, 2005.

MARQUES, Tania Beatriz Iwaszko. Professor ou pesquisador? In: BECKER, Fernando; MARQUES, Tania Beatriz Iwaszko (org.). Ser professor é ser pesquisador. Porto Alegre: Mediação, 2010. p. 56-62.

MONTEIRO, Silas Borges. Epistemologia da prática: o professor reflexivo e a pesquisa colaborativa. In: PIMENTA, Selma Garrido; GHEDIN, Evandro (org.). Professor reflexivo no Brasil: gênese e crítica de um conceito. São Paulo: Cortez, 2012. p. 128-147.

MORAES, Maria Cândida; VALENTE, José Armando. Como pesquisar em educação a partir da complexidade e da transdisciplinaridade? São Paulo: Paulus, 2008.

MORIN, Edgar; VIVERET, Patrick. Como viver em tempo de crise? Rio de Janeiro: Bertrand Brasil, 2013.

NÓVOA, António. Firmar a posição como professor, afirmar a profissão docente. Cadernos de Pesquisa, Curitiba, v. 47, n. 166, p. 1106-1133, out./dez. 2017.

O TEMPO não para. [Compositor e intérprete]: Cazuza. Rio de Janeiro: PolyGram Universal Music, 1988. 1 CD. (43min.26).

SIMPLES assim. [Compositor e intérprete]: Lenine. Rio de Janeiro: Universal Music, 2015. 1 CD. (39min28).

TARDIF, Maurice. A profissionalização do ensino passados trinta anos: dois passos para a frente, três para trás. Educação e Sociedade, Campinas, v. 34, n. 123, p. 551-571, abr./jun. 2013.

TARDIF, Maurice. Saberes docentes e formação profissional. Petrópolis: Vozes, 2014.

TEIXEIRA, Elizabeth. As três metodologias: acadêmica, da ciência e da pesquisa.

Petrópolis: Vozes, 2009.

VLACH, Vânia Rúbia Farias. Geografia em debate. Belo Horizonte: Lê, 1990. 
VLACH, Vânia Rúbia Farias. Geografia em construção. Belo Horizonte: Lê, 1991.

Recebido: julho de 2021. Aceito: novembro de 2021. 